\title{
Study on the Mechanical Properties and Thermal Conductivity of Cotton Stalk Fiber Heat-Insulating Shotcrete
}

\author{
Guangcheng Liu $\mathbb{D}^{1,2}$ Weijing Yao, ${ }^{1,2}$ and Jianyong Pang ${ }^{1,2}$ \\ ${ }^{1}$ State Key Laboratory of Mining Response and Disaster Prevention and Control in Deep Coal Mines, \\ Anhui University of Science and Technology, Huainan 232001, China \\ ${ }^{2}$ School of Civil Engineering and Architecture, Anhui University of Science and Technology, Huainan 232001, China \\ Correspondence should be addressed to Guangcheng Liu; 850413020@qq.com
}

Received 28 July 2021; Revised 9 January 2022; Accepted 28 January 2022; Published 18 February 2022

Academic Editor: Hao Yi

Copyright (c) 2022 Guangcheng Liu et al. This is an open access article distributed under the Creative Commons Attribution License, which permits unrestricted use, distribution, and reproduction in any medium, provided the original work is properly cited.

\begin{abstract}
In this study, heat-insulating shotcrete with excellent performance was developed to effectively reduce the thermal conductivity and meet the strength requirements of shotcrete in high ground temperature roadways. Ceramsite and pottery sand were used to replace $5 \%$ and $10 \%$ of sand and stone, respectively. The shotcrete was composed of cotton rod fiber treated with polyvinyl alcohol solution (SH adhesive) and other materials in a certain mix ratio. The working, mechanical, and heat insulation properties of the shotcrete were investigated by compressive strength, splitting tensile, thermal conductivity, electron microscope scanning, and $\mathrm{X}$-ray diffraction tests. The results showed that the optimum content of the cotton stalk fiber was $2 \mathrm{~kg} / \mathrm{m}^{3}$. The compressive strength and the splitting tensile properties were excellent, and the strength attained the maximum value. The performance of shotcrete increased with an increase in the cotton stalk fiber content. The thermal conductivity curve decreased smoothly when the cotton stalk fiber content exceeded $2 \mathrm{~kg} / \mathrm{m}^{3}$. Furthermore, when the cotton stalk fiber content was $0-2 \mathrm{~kg} / \mathrm{m}^{3}$, the internal cotton stalk fiber was tightly wrapped by the hydrate, and the mechanical properties were enhanced. Moreover, when the cotton stalk fiber content was $2-3 \mathrm{~kg} / \mathrm{m}^{3}$, a clustering phenomenon occurred, and the compressive and tensile strengths were reduced. The hydration reaction of the cement mixed with cotton stalk fiber was normal, and the reinforced reticulated porous structure was formed with ceramsite in the concrete matrix, improving the strength of the concrete and reducing the thermal conductivity.
\end{abstract}

\section{Introduction}

As the depth of coal mines increases, the rock temperature and thermal conductivity of the deep rock mass gradually increase [1]. After tunnel excavation, the heat exchange between the surrounding rock and the air can cause thermal stress. Moreover, an increase in the ground temperature triggers an increase in the thermal stress in the surrounding rock during tunnel excavation. Consequently, several new cracks are generated, and the stress distribution of the surrounding rock is changed. An increase in tangential stress, displacement, broken area, and the radius of the plastic zone around the deeply buried roadway impacts the roadway's safety negatively [2-4], causing enormous thermal disasters [5-12]. By adding admixture, shotcrete can be used as a lining layer of the roadway to meet the strength requirements and reduce the thermal conductivity of the roadway [13, 14]. Furthermore, shotcrete can provide support for the roadway and effectively prevent heat dissipation of the surrounding rock. Shotcrete is treated using some common methods. First, different fibers, such as steel, polypropylene, and basalt fibers [15], are added to shotcrete, but their effect on reducing the thermal insulation performance of concrete is unapparent. Second, the concrete aggregate is partly replaced with porous materials, such as ceramsite, glass, and polystyrene beads, to reduce the thermal conductivity of the concrete. However, porous materials will considerably reduce the concrete strength; thus, the machinability and molding difficulty will be poor [16]. Additionally, the lightweight properties of glass and 
polystyrene beads make them float and separate during mixing and vibration, which can adversely affect the processing and mechanical properties of concrete [17, 18]. Third, a plant fiber is added to concrete to form a composite reinforcement material to improve the concrete strength [19]. The inherent multiscale cell wall of plant fiber and the inner cavity structure can also reduce the thermal conductivity of concrete [20]. However, plant fiber has poor corrosion resistance, and the alkaline substance produced by the hydration of the cement in the system after the plant fiber is incorporated degrades easily, resulting in a lower concrete poststrength and less durability.

The low thermal conductivity [19] of plant fiber and its good compatibility with the concrete matrix $[21,22]$ can further reduce the thermal conductivity of the shotcrete. Plant fibers are generally used as a silt soil reinforcement material [23]. When plant fiber is mixed with concrete, the internal reticular structure of concrete produces a secondary reinforcement effect, which improves the concrete strength and reduces the spring back caused by ceramsite ceramic sand. Therefore, in this study, cotton rod fiber (plant fiber: PL) was mixed with the ceramsite ceramic sand concrete to prepare a new type of thermal insulation shotcrete. Unconfined compressive strength, split tensile, thermal conductivity, scanning electron microscope (SEM), and X-ray diffraction (XRD) tests were conducted to examine the working, mechanical, and thermal insulation properties of the new thermal insulation shotcrete. Few studies have investigated the influence of different cotton rod fiber mixtures on the performance of heat insulation concrete. The newly developed shotcrete can prevent the heat dissipation of the surrounding rock of the high ground temperature roadway; the shotcrete can also improve the thermal environment of the coal mine roadway.

Few studies have investigated the influence of different cotton rod fiber mixtures on the performance of heat insulation concrete. The different plant fiber mix proportions were designed in this paper for newly developed shotcrete. It is different from previous studies that compared different kinds of fiber mixed into concrete. This search focuses on the influence of different plant fiber contents on concrete materials. Also, the newly developed shotcrete can prevent the heat dissipation of the surrounding rock of the high ground temperature roadway; the shotcrete can also improve the thermal environment of the coal mine roadway.

\section{Materials and Methods}

2.1. Materials. The plant fiber used in this study was the cotton stalk fiber from the salt city of Jiangsu Province and processed by the Yancheng Institute of Technology. An anticorrosion treatment was required because the biological characteristics of the cotton stalk fiber can cause poor corrosion resistance and less durability of the concrete system $[19,23]$. Modified polyvinyl alcohol (SH adhesive) was selected to prevent poor corrosion resistance $[24,25]$. First, the cotton rod fibers of each length were dried in a box and soaked in saturated $\mathrm{SH}$ adhesive for three days.
Thereafter, the rod fibers were washed with anhydrous ethanol and dried naturally [24]. Figure 1 shows fiber anticorrosion treatment and the contrasting diagram of SEM before and after the treatment. As can be observed in Figure 1(a), the surface of the fiber was rough and contained numerous holes before the treatment. Figure 1(b) shows the soaking of the SH glue. As shown in Figure 1(c), SH adhesive formed a solidified film on the surface of the fiber, encapsulating the fiber in the film to prevent direct contact between the fiber and the outside water and air. This phenomenon improved the stability and corrosion resistance of the cotton rod fiber. Table 1 presents the main chemical components of the cotton stalk fiber.

The cement used was P.O 42.5 Ordinary Portland Cement (Bagongshan Cement Plant, Huainan City). The burning loss was $2.0 \%$, the fineness of cement was $4.5 \%$, the stability was high, and the hydration heat was low. The main chemical components are presented in Table 2. The test aggregate was obtained from Huainan, Anhui, China, and was mainly composed of the following: (1) the sand (river sand) used for fine aggregate with a fineness modulus of 2.8; (2) coarse aggregate $(5-10 \mathrm{~mm}$ melon seed stone) with a crushing index of $7.5 \%$ (Table 3 presents sand and stone performance parameter index); and (3) haydite and pottery sand, which were the main substances to replace coarse aggregate and fine aggregate, respectively. The test additive was composed of two components: (1) class I fly ash produced by a coal-fired power plant in Anhui, China, with a fineness content of $10 \%$ (the ash quality index is shown in Table 4). (2) The water-reducing agent of the polycondensing acid. Tap water was the mixing water. All materials were selected based on the technical specifications for the application of shotcrete (JGJ/T 372-2016) [26, 27].

2.2. Mix Ratio. The experiment was based on a concrete mix ratio of $\mathrm{C} 30$ shotcrete. Ceramsite and sand were used for replacing $5 \%$ of the stone mass and $10 \%$ of the sand mass, respectively. The cotton stalk fiber was added to each concrete group according to $0,0.5,1.0,1.5,2.0,2.5$, and $3.0 \mathrm{~kg} / \mathrm{m}^{3}$. The raw material consumption of each group is shown in Table 5.

2.3. Preparation of Test Blocks. The compressive strength, tensile strength, and thermal conductivity of each concrete group were measured. In compliance with the construction quality requirements of structural engineering concrete, seven groups of ordinary concrete test blocks (design size, $100 \mathrm{~mm} \times 100 \mathrm{~mm} \times 100 \mathrm{~mm}$ ) and three parallel blocks were used in each group to minimize error. The compressive and splitting tensile strengths were determined for each group. Therefore, to measure the thermal conductivity, each group contained six test blocks (making a total of 42 test blocks), and seven groups contained 21 test blocks (design size, $300 \mathrm{~mm} \times 300 \mathrm{~mm} \times 300 \mathrm{~mm}$ ). The unconfined compressive strength and thermal conductivity of concrete were measured using WAW-2000 electrohydraulic servo universal instrument and PDR-300 thermal conductivity instrument after curing the test blocks in a saturated $\mathrm{Ca}(\mathrm{OH})_{2}$ solution 


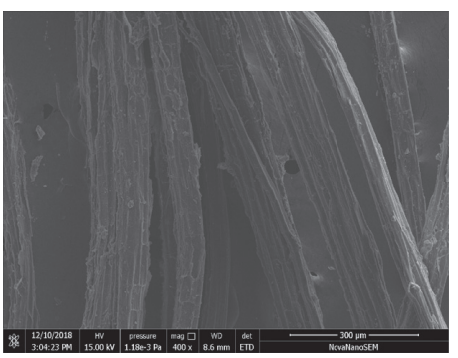

(a)

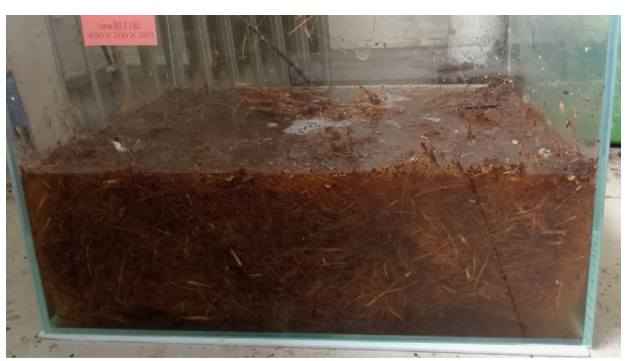

(b)

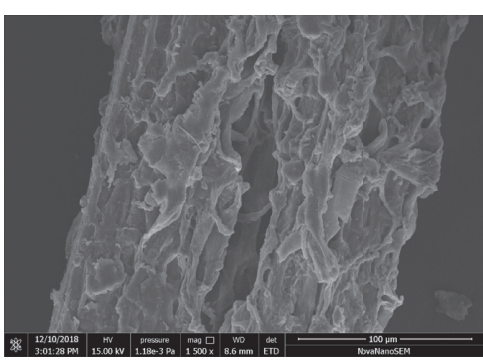

(c)

Figure 1: SEM comparison of PL before and after anticorrosion treatment: (a) before, (b) during, and (c) after.

TABLE 1: Main chemical components of cotton stalk fiber.

\begin{tabular}{lcccc}
\hline Chemical constituent & Holocellulose & Klasson lignin & Ash content & Benzene-alcohol extract \\
\hline Content $(\%)$ & 70.26 & 22.29 & 5.60 & 1.86 \\
\hline
\end{tabular}

TABle 2: Chemical composition of cement.

\begin{tabular}{lccccc}
\hline Chemical constituent & $\mathrm{SO}_{3}$ & $\mathrm{MgO}$ & $\mathrm{K}_{2} \mathrm{O}$ & $\mathrm{Na}_{2} \mathrm{O}$ & Loss on ignition \\
\hline Content (\%) & 3.20 & 1.66 & 0.63 & 0.36 & 2.54 \\
\hline
\end{tabular}

TABLe 3: Quality index of sand and stone.

\begin{tabular}{lcccc}
\hline Project & Sediment percentage $(\%)$ & Stacking density $\left(\mathrm{kg} / \mathrm{m}^{3}\right)$ & Particle size range $(\mathrm{mm})$ & Apparent density $\left(\mathrm{g} / \mathrm{cm}^{3}\right)$ \\
\hline Sand & $\leq 2$ & 1470 & $0.16-1.0$ & 2690 \\
Cobblestone & $\leq 0.2$ & 1580 & $5-10$ & 2700 \\
\hline
\end{tabular}

TABle 4: Quality index of fly ash.

\begin{tabular}{lccccc}
\hline Project & Fineness (\%) & Water demand (\%) & Loss on ignition (\%) & Free calcium oxide (\%) & SO $_{3}$ content (\%) \\
\hline Detection result & 8 & 95 & 5 & $\leq 1$ & $\leq 3$ \\
\hline
\end{tabular}

TABle 5: Mix proportion design of plant fiber shotcrete $\left(\mathrm{kg} / \mathrm{m}^{3}\right)$.

\begin{tabular}{lccccccccc}
\hline Number & Cement & Cotton straw fiber & Fly ash & Haydite & Pottery sand & Cobblestone & Sand & Water & Water reducer \\
\hline C & 425.7 & 0 & 49.5 & 41.6 & 83.1 & 789.0 & 747.5 & 212.9 & 3.9 \\
PL1 & 425.7 & 0.5 & 49.5 & 41.6 & 83.1 & 789.0 & 747.5 & 212.9 & 3.9 \\
PL2 & 425.7 & 1.0 & 49.5 & 41.6 & 83.1 & 789.0 & 747.5 & 212.9 & 3.9 \\
PL3 & 425.7 & 1.5 & 49.5 & 41.6 & 83.1 & 789.0 & 747.5 & 212.9 & 3.9 \\
PL4 & 425.7 & 2.0 & 49.5 & 41.6 & 83.1 & 789.0 & 747.5 & 212.9 & 3.9 \\
PL5 & 425.7 & 2.5 & 49.5 & 41.6 & 83.1 & 789.0 & 747.5 & 212.9 & 3.9 \\
PL6 & 425.7 & 3.0 & 49.5 & 41.6 & 83.1 & 789.0 & 747.5 & 212.9 & 3.9 \\
\hline
\end{tabular}

for 28 days. The measurements were performed in compliance with the test standards for mechanical properties of ordinary concrete (GB/T 50081-2002).

\section{Evaluation of Test Results}

3.1. Test Results. The test results of the compressive strength, tensile strength, and thermal conductivity of each group of samples are presented in Table 6 .

Table 6 illustrates that the shotcrete compressive and tensile strengths increased first and then decreased with an increase in the cotton stalk fiber content. However, the thermal conductivity decreased gradually with an increase in the cotton stalk fiber. When the cotton stalk fiber content was $2.0 \mathrm{~kg} / \mathrm{m}^{3}$, the shotcrete compressive and tensile strengths attained maximum values of 39.6 and $2.72 \mathrm{MPa}$, respectively, and then decreased gradually. With an increase in the cotton fiber content, the shotcrete thermal conductivity decreased continuously. Furthermore, when the cotton fiber content was $3.0 \mathrm{~kg} / \mathrm{m}^{3}$, the thermal conductivity was the lowest, with a minimum value of $0.3072 \mathrm{~W} \cdot(\mathrm{K} \cdot \mathrm{m})^{-1}$, while the compressive and tensile strengths were 36.5 and 2.47 $\mathrm{MPa}$, respectively.

3.2. Compressive Strength Test. Figure 2 shows that the shotcrete compressive strength can be improved by adding a certain amount of cotton stalk fiber. For instance, when the 
TABle 6: Physical and mechanical parameters of shotcrete.

\begin{tabular}{lccccccccc}
\hline No. & $\begin{array}{c}\text { Fiber } \\
\text { content } \\
\left(\mathrm{kg} \cdot \mathrm{m}^{-3}\right)\end{array}$ & $\begin{array}{c}\text { Compressive } \\
\text { strength }(\mathrm{MPa})\end{array}$ & $\begin{array}{c}\text { Increase } \\
\text { amplitude } \\
(\%)\end{array}$ & $\begin{array}{c}\text { Tensile } \\
\text { strength } \\
(\mathrm{MPa})\end{array}$ & $\begin{array}{c}\text { Increase } \\
\text { amplitude } \\
(\%)\end{array}$ & $\begin{array}{c}\text { Thermal } \\
\text { conductivity } \\
\left(\mathrm{w}{ }^{*} \mathrm{k} / \mathrm{m}\right)\end{array}$ & $\begin{array}{c}\text { Increase } \\
\text { amplitude } \\
(\%)\end{array}$ & $\begin{array}{c}\text { Bending } \\
\text { resistance } \\
(\mathrm{MPa})\end{array}$ & $\begin{array}{c}\text { Amplification } \\
(\%)\end{array}$ \\
\hline C & 0 & 33.7 & 0 & 2.28 & 0 & 0.3988 & 0 & 3.21 & 0 \\
PL1 & 0.5 & 35.6 & 5.7 & 2.45 & 7.5 & 0.3689 & -7.3 & 3.58 & 11.53 \\
PL2 & 1.0 & 37.8 & 12.0 & 2.59 & 13.7 & 0.3474 & -13.0 & 3.79 & 18.07 \\
PL3 & 1.5 & 39.1 & 15.8 & 2.69 & 18.1 & 0.3279 & -17.3 & 3.98 \\
PL4 & 2.0 & 39.6 & 17.4 & 2.73 & 20.3 & 0.3183 & -20.6 & 4.26 & 32.99 \\
PL5 & 2.5 & 38.0 & 12.8 & 2.62 & 15.0 & 0.3101 & -22.1 & 3.87 & 18.69 \\
PL6 & 3.0 & 36.5 & 8.3 & 2.48 & 10.0 & 0.3072 & -22.9 & 3.59 & 11.84 \\
\hline
\end{tabular}

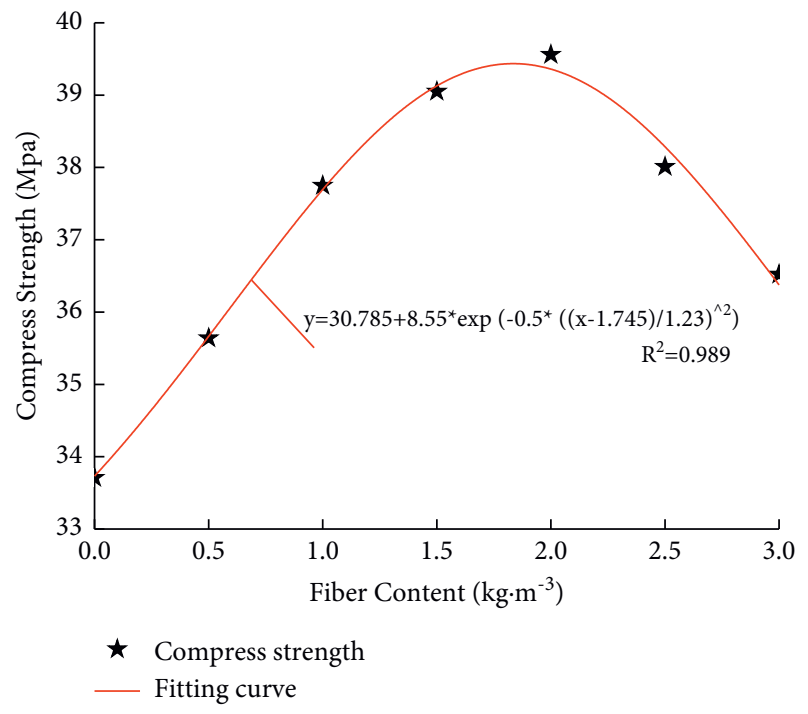

FIGURE 2: Compressive strength fitting curve.

dosage was $0.5-2.0 \mathrm{~kg} / \mathrm{m}^{3}$, the concrete compressive strength increased by $5.7 \%-17.4 \%$; when the dosage was $2.5-3.0 \mathrm{~kg} /$ $\mathrm{m}^{3}$, the concrete compressive strength decreased. A small amount of cotton stalk fiber and concrete matrix had a more reliable cementation synergy, improving the concrete's compressive strength [18]. However, with an increase in the cotton stalk fiber content, agglomerations inside the concrete were inevitable. The agglomerations resulted in an uneven distribution of cement paste, poor matrix, and workability. The concrete's internal porosity was increased, causing a decrease in the concrete's compressive strength. Cotton fiber contributed to the concrete's compressive strength with a critical content of $2 \mathrm{~kg} / \mathrm{m}^{3}$.

The load-displacement data corresponding to the compressive and splitting tensile strengths of the cotton stalk fiber concrete were used to fit the $\sigma$ - $\varepsilon$ curve during the stress process of the test piece. The fitting was performed using Origin 9.0, as shown in Figure 3.

Figure 3 illustrates that the cotton stalk fiber concrete underwent the elastic stage, elastic-plastic stage, peak stress point, and plastic failure section. When the mixing amount was $0-2 \mathrm{~kg} / \mathrm{m}^{3}$ with an increase in the fiber dosage, the peak stress increased continuously, while the corresponding limit strain increased. When the mixing amount was $2-3 \mathrm{~kg} / \mathrm{m}^{3}$, the peak stress decreased, while the corresponding limit strain decreased. The stress-strain curve

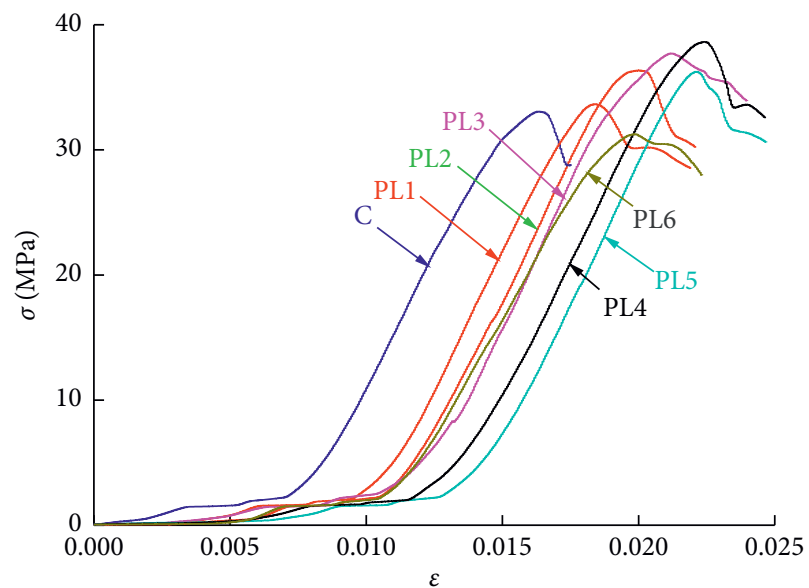

FIGURE 3: Compressive strength stress-strain curve.

after the peak stress shows that the curve of the concrete with cotton stalk fiber was gentler than that without the cotton stalk fiber.

Figure 4 illustrates that, under pressure, the cotton stalk fiber concrete had high structural integrity. With an increase in fiber content, the degree of spalling on the surface of the test block decreased, the integrity improved, and the strength increased. However, the concrete surface without cotton fiber was broken and peeled off in many parts. Additionally, the concrete surface had deep cracks and angular peeling, demonstrating that cotton fiber improved the concrete compressive strength and structural integrity, reduced the concrete brittleness, and enhanced the concrete toughness.

3.3. Splitting Tensile Test. Figure 5 shows that the concrete splitting tensile property was improved by adding cotton stalk fiber. When the mixing amount was $0.5-2.0 \mathrm{~kg} / \mathrm{m}^{3}$, the concrete tensile strength increased by $7.5 \%-20.3 \%$. Furthermore, when the mixing amount was more than $2 \mathrm{~kg} / \mathrm{m}^{3}$, the concrete tensile strength decreased gradually. The bond with the concrete matrix can be enhanced by adding an appropriate amount of cotton fiber, thus enhancing the tensile strength [18]. However, adding excessive cotton fiber weakens the tensile strength. Therefore, cotton fiber contributed to the concrete tensile strength with a critical content of $2 \mathrm{~kg} / \mathrm{m}^{3}$ (corresponding to a concrete tensile strength of $2.74 \mathrm{MPa})$. 


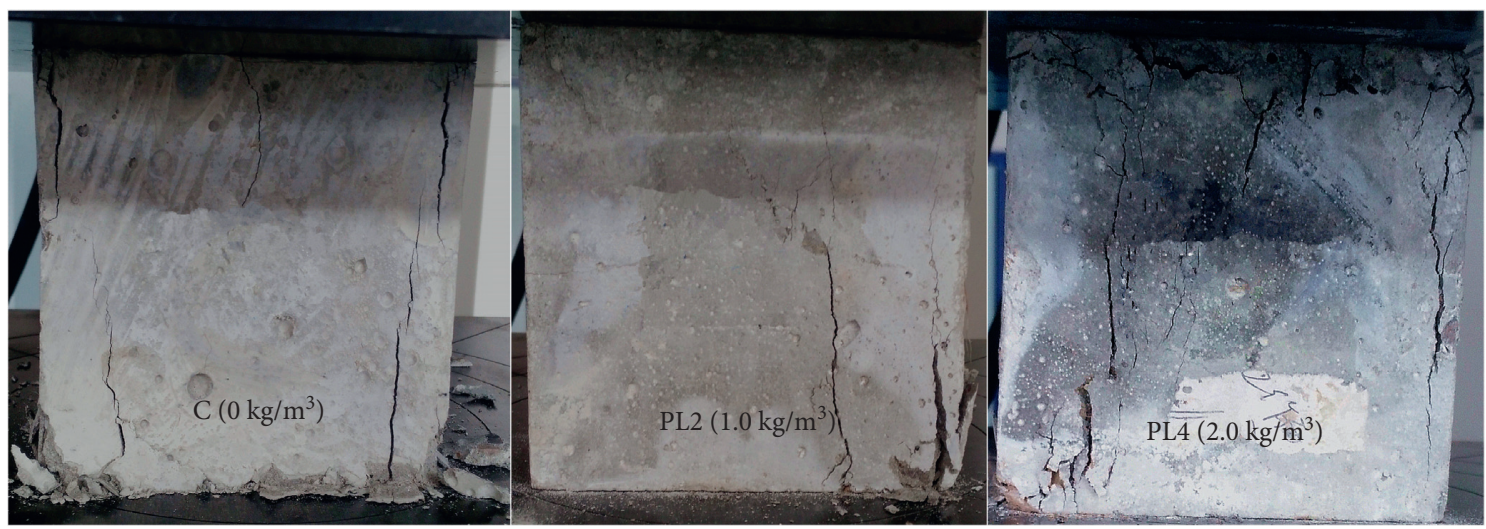

FIGURE 4: Failure mode of compression specimen.

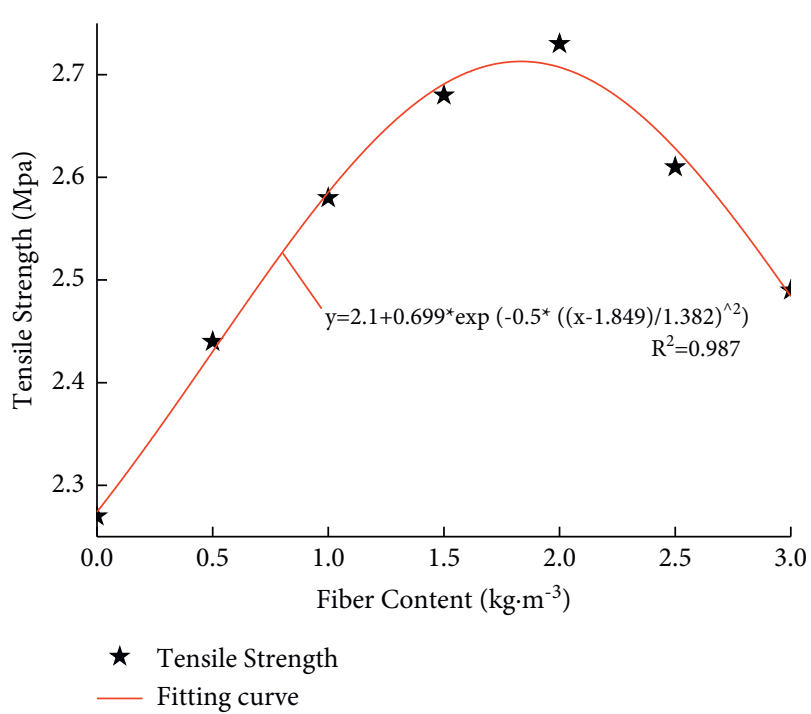

FIgURE 5: Splitting tensile strength fitting curve.

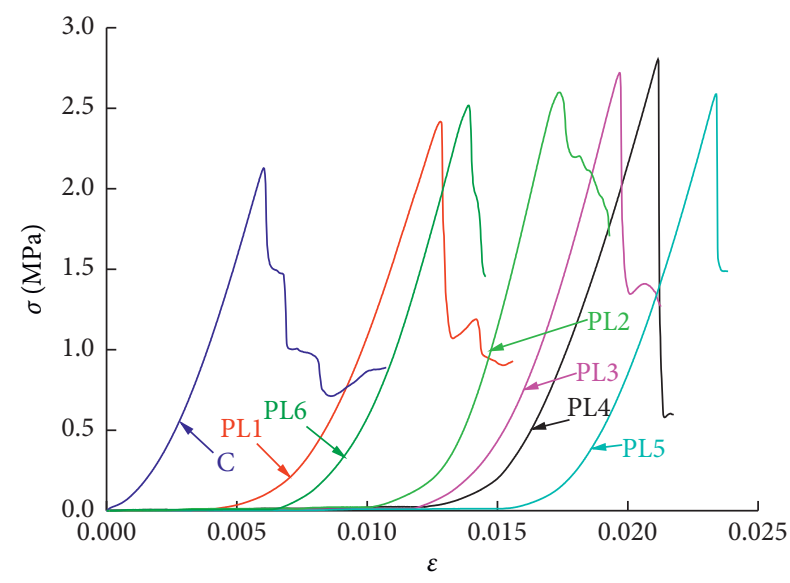

FIGURE 6: PL/SC splitting tensile strength stress-strain curve.

As can be observed in Figure 6, the peak stress of the curve increased continuously with an increase in the cotton stalk fiber content, and the corresponding ultimate strain also increased. When the cotton stalk fiber content was $2 \mathrm{~kg} / \mathrm{m}^{3}$, the maximum stress peak value was $2.74 \mathrm{MPa}$. Furthermore, when the cotton stalk fiber content was $2.5 \mathrm{~kg} / \mathrm{m}^{3}$, the maximum ultimate strain variable was $2.38 \times 10^{-2}$.

Figure 7 illustrates that the crack width and depth in the fiber-reinforced concrete test block were smaller and less than those in ordinary haydite concrete.

3.4. Concrete Tension-Compression Ratio. Figure 8 illustrates the concrete tension-compression ratio (corresponding to different dosages), which intuitively expresses the influence of cotton stalk fiber on the tension and compression performance of shotcrete. The figure illustrates that adding cotton stalk fiber can improve the concrete tension-compression ratio. With an increase in fiber content, the tension-compression ratio increased because the cotton stalk fiber restrains the development of microcracks and bears certain tensile stress. When the fiber content was less than $2.0 \mathrm{~kg} / \mathrm{m}^{3}$, the fiber distribution in the shotcrete was more even, and it was easier to form a multidirectional spatial structure. The cotton stalk fiber and concrete were an effective combination that improved the shotcrete tensile performance and toughness.

3.5. Thermal Conductivity Test. Cotton stalk fiber has good heat preservation performance and low thermal conductivity. By adding cotton stalk fiber to concrete, the air convection and radiation heat transfer performances between the hole walls in the concrete can be improved [5], and the concrete thermal conductivity can be reduced. Consequently, the thermal insulation performance of shotcrete can be improved.

As illustrated in Figure 9, the shotcrete thermal conductivity decreased continuously with an increase in cotton stalk fiber content. Compared with the control experiment, when the cotton stalk fiber content was $2,2.5$, and $3.0 \mathrm{~kg} / \mathrm{m}^{3}$, the thermal conductivity decreased by $20.61 \%, 22.09 \%$, and $22.9 \%$, respectively.

Cotton stalk fiber is an excellent insulation material with low thermal conductivity. The cotton stalk fiber was added to the concrete to enhance the convection heat transfer of air inside the concrete and the radiation heat transfer between the hole walls; this enhancement can reduce the concrete thermal conductivity and improve the thermal insulation performance $[28,29]$. 


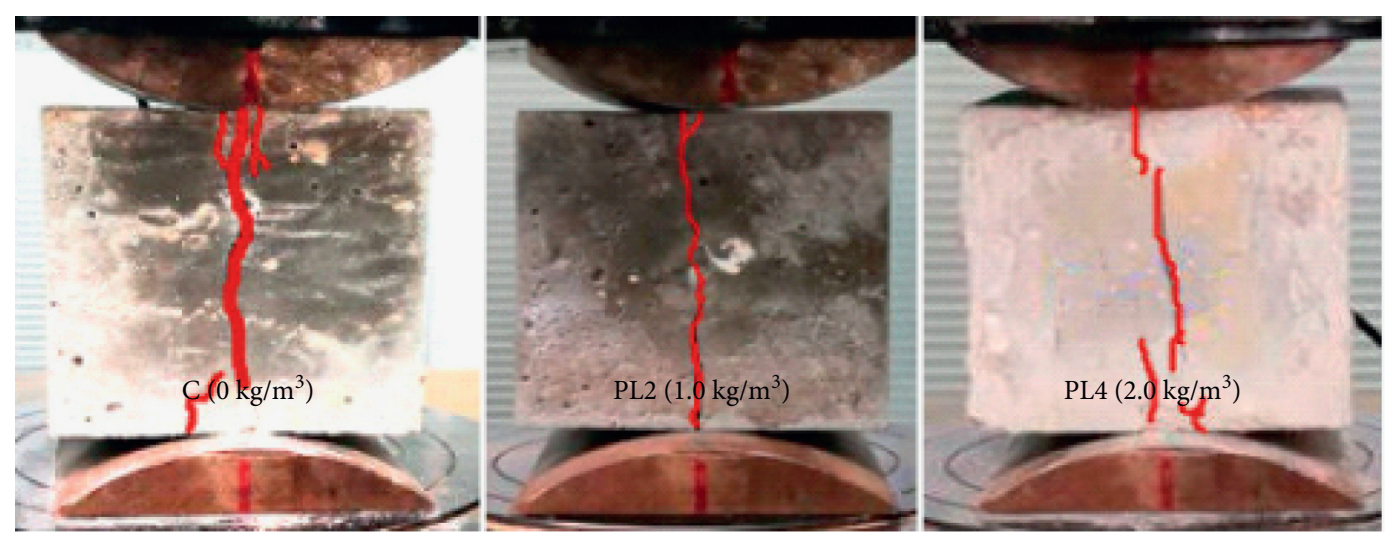

FIgURE 7: Failure mode of the tension specimen.

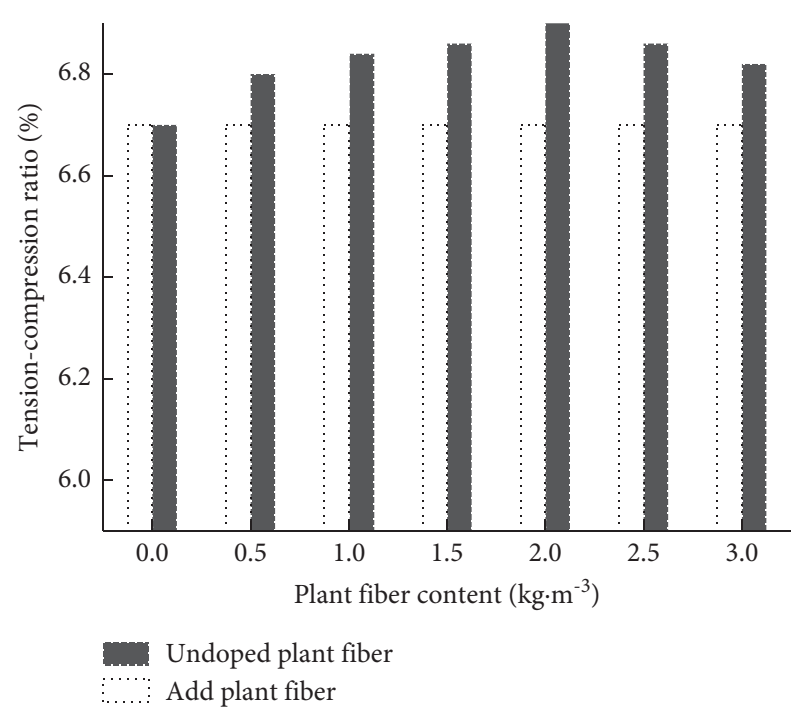

FIgURE 8: Comparison of tension-compression ratio.

\section{Microcosmic Analysis}

To spray shotcrete onto the layer of a high-temperature roadway support, the shotcrete requires the necessary mechanical strength and low thermal conductivity. Through microanalysis, the interaction between the admixture and the cement paste in the injected concrete matrix was observed. Macroscopic and microtests were used to analyze the effect of the composition components on the mechanical strength and thermal conductivity of the sprayed concrete. The tests were conducted using the small, crushed pieces. The observation sample was the interface part of the sprayed concrete cement mortar and the cotton stalk fiber. The content of the components and hydration reaction components in the concrete were analyzed by XRD. Using SEM, the intuitionistic morphology of the concrete matrix was observed, and the relationship between macrostructure and microstructure was analyzed in more detail. Additionally, the relationship between the components of cotton stalk fiber-sprayed concrete was determined. Finally, the mechanism for improving concrete strength and reducing thermal conductivity by using cotton stalk fiber was analyzed more comprehensively.
4.1. X-Ray Diffraction Analysis. The cotton stalk fiber content differed throughout the seven groups of thermal insulation shotcrete. Based on the previous test, the optimum cotton stalk fiber content in shotcrete was $2.0 \mathrm{~kg} / \mathrm{m}^{3}$ (corresponding to the PL-4 specimen). For XRD comparison and analysis, PL-3, PL-4, and PL-5 were marked as 1\#, 2\#, and 3\#, respectively. The samples were sealed after grinding, and they were passed through a 400-mesh screen. The test results are shown in Figure 10.

The vertical axis of Figure 10 represents the content value of the corresponding element, and the horizontal axis represents the diffraction angle range. Samples numbered 1\#, 2\#, and $3 \#$ were in the same test environment. Consistent with the study in references [30,31], the XRD spectra of the three groups of samples showed $2 \mathrm{Aft}$ and $1 \mathrm{Ca}(\mathrm{OH})_{2}$ ) peaks. The height of peak $B$ of sample 2 was higher than that of peak $\mathrm{A}$, and the alunite content was greater than that of $\mathrm{Ca}(\mathrm{OH})_{2}$. The alunite peak height in sample 2\# was the largest. Therefore, the compressive strength of sample 2\# was the largest and was consistent with the compressive strength test result. The porcelain granule contains a certain amount of clay mineral and can be reacted with $\mathrm{Ca}(\mathrm{OH})_{2}$ of the main hydration product of the cement to form calcium stone. The alunite content was increased to reduce the calcium hydroxide content. Additionally, because the concrete was mixed with ceramsite, ceramic sand, fly ash, and other mineral admixtures, several free elements in each admixture reacted to form two kinds of polymers: $5 \mathrm{Al}(\mathrm{OH})_{3} \cdot \mathrm{AlPO}_{4}$ and 7.2 $\mathrm{MgSO}_{4} \mathrm{Mg}(\mathrm{OH})_{2}$. These polymers are flame retardants with high strength, stable size, and crack resistance $[32,33]$.

4.2. Scanning Electron Microscope Analysis. The SEM images in Figure 11 represent the cross section of the insulating concrete matrix. The cement hydration product was hydrated calcium aluminate; the secondary cement hydration product was the alunite. The hydration products closely wrapped the cotton stalk fiber, which was inserted into the concrete. Figure 11 illustrates an even distribution with red arrows highlighting the product. The cotton stalk fiber was tightly wrapped by the hydrate, forming a stable spatial 


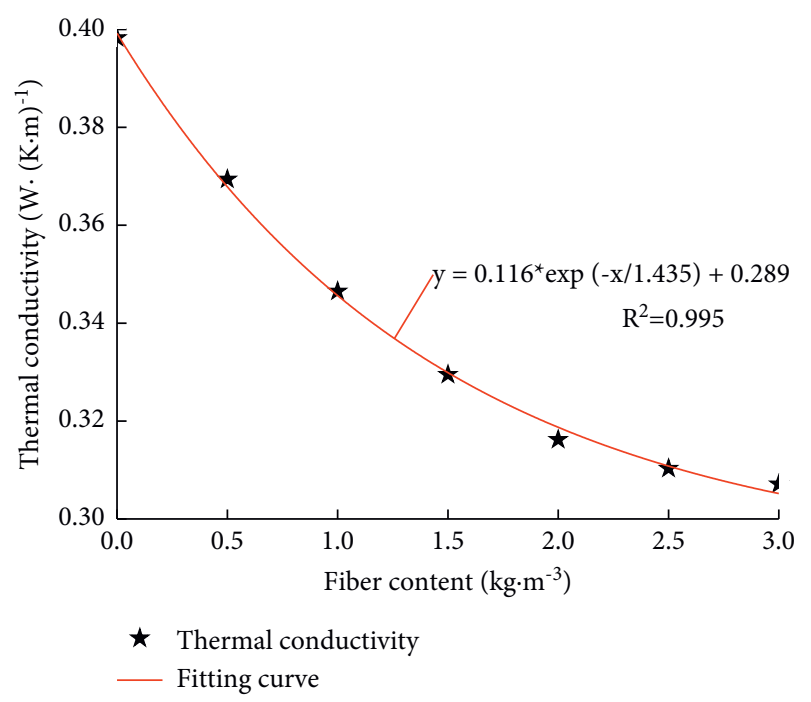

FIgURe 9: Thermal conductivity fitting curve.

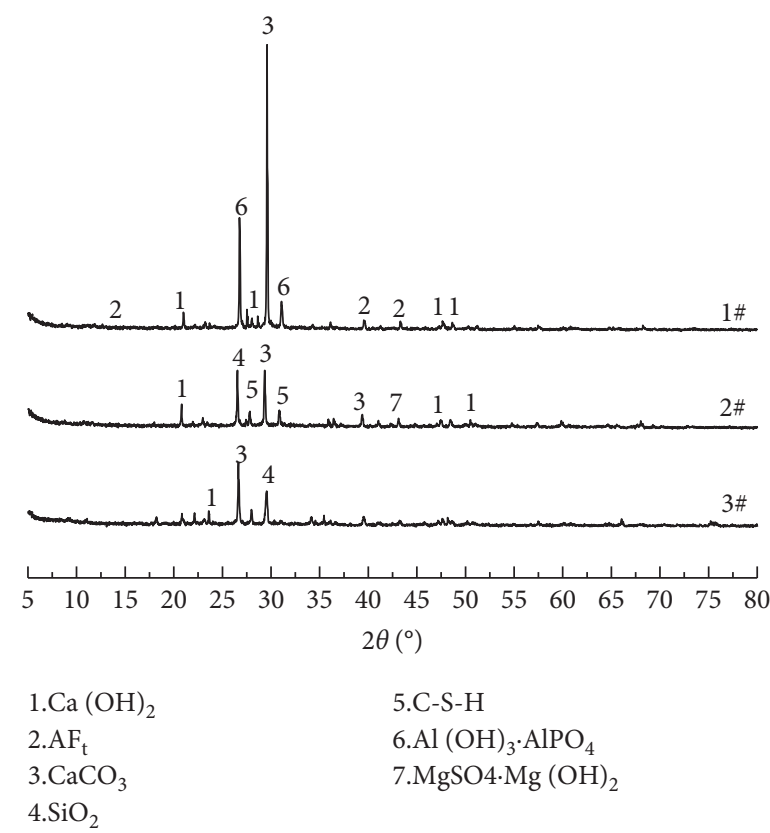

Figure 10: Qualitative analysis of X-ray diffraction results of samples 1\#, 2\#, and 3\#.

structure when combined with the shotcrete matrix. This structure played the role of secondary microreinforcement, thus improving the mechanical properties of concrete. Moreover, the multidirectional spatial distribution of cotton stalk fiber in concrete was beneficial for forming a stable mesh structure and enhancing the overall shotcrete structure.

Adding ceramsite and pottery sand reduced the concrete thermal conductivity to a certain extent, whereas it weakened the concrete strength, which is determined by the characteristics of the porous materials. When the correct amount of cotton stalk fiber was added to the concrete, the strength of the sprayed concrete was improved. The strength attained a maximum value when the content was $2 \mathrm{~kg} / \mathrm{m}^{3}$, and the PL- 6 test piece with $3 \mathrm{~kg} / \mathrm{m}^{3}$ of cotton stalk fiber was selected for SEM. As shown in Figure 12, the cotton rod fibers clustered, affecting the full bond of the concrete matrix. The agglomerated fibers also increased the concrete internal defects, affected the concrete performance, and decreased the concrete strength. 


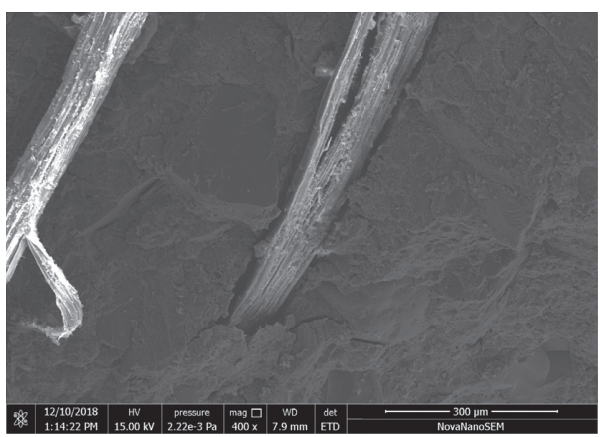

(a)

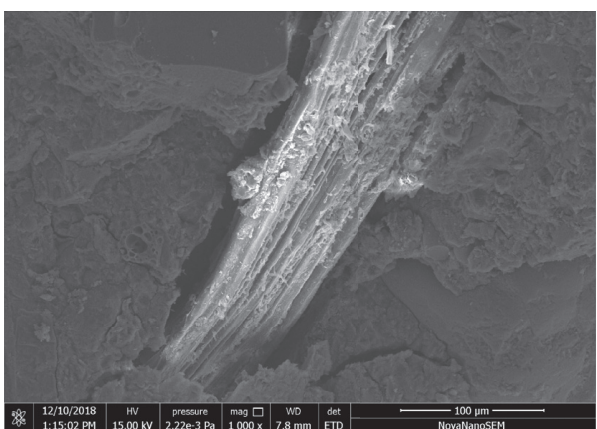

(b)

Figure 11: Bonding between PL and matrix.

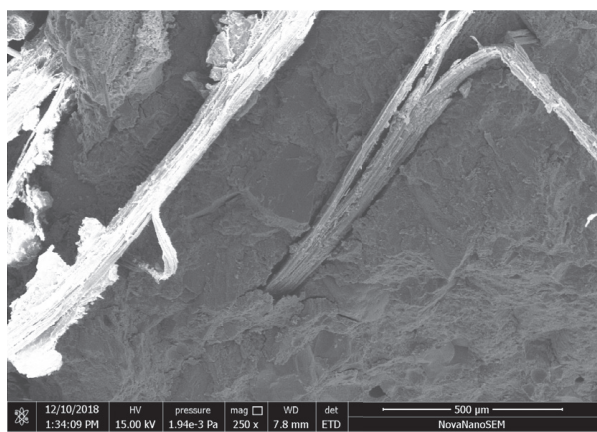

(a)

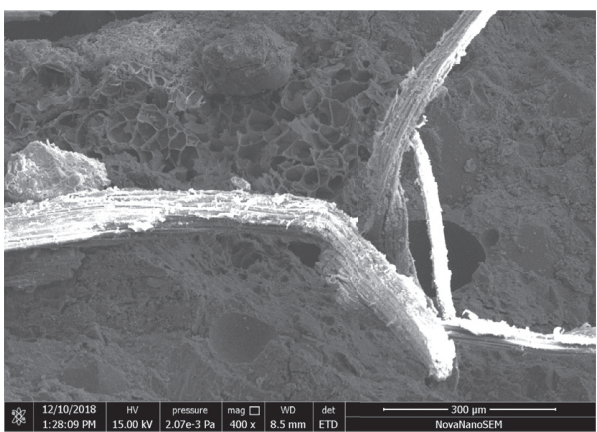

(b)

FIGURE 12: Distribution and bonding image.

\section{Conclusion}

The following conclusions can be made based on the experimental results of the physical and mechanical properties of thermal insulation shotcrete:

(1) As cotton stalk fiber content increased, the compressive and tensile strengths of shotcrete first increased and then decreased. When the content of cotton stalk fiber was $2 \mathrm{~kg} / \mathrm{m}^{3}$, the shotcrete compressive and split tensile properties were excellent, and the strength attained maximum values of 39.56 and $2.73 \mathrm{MPa}$, respectively.

(2) Compared with the shotcrete without cotton stalk fiber, the shotcrete thermal conductivity decreased gradually with an increase in cotton stalk fiber content, implying that the shotcrete thermal insulation performance increased with an increase in cotton stalk fiber content. When the content exceeded $2 \mathrm{~kg} / \mathrm{m}^{3}$, the shotcrete thermal conductivity curve decreased smoothly. Thus, the experimental results of the compressive and tensile strengths of shotcrete showed that the optimum cotton stalk fiber content was $2 \mathrm{~kg} / \mathrm{m}^{3}$.

(3) The morphology of the interface transition zone between thermal insulation shotcrete cement mortar and cotton stalk fiber was analyzed. The results showed that when the cotton stalk fiber content was $0-2 \mathrm{~kg} / \mathrm{m}^{3}$, the cotton stalk fiber was more tightly wrapped by the hydrate, and the mechanical properties were gradually enhanced. When the cotton stalk fiber content was $2-3 \mathrm{~kg} / \mathrm{m}^{3}$, the cotton stalk fiber had the agglomeration phenomenon, and the shotcrete compressive strength decreased. The hydration reaction of cement mixed with cotton stalk fiber was normal, and the reinforced reticulated porous structure was formed with ceramsite in the concrete matrix, which improved the concrete strength and reduced the thermal conductivity.

(4) The cotton stalk fiber heat-insulating shotcrete developed in this study is mainly intended for enhancing the thermal insulation performance of tunnel and roadway lining structures. Therefore, the developed materials can be widely applied.

\section{Data Availability}

The data used to support the findings of this study are included within the article.

\section{Conflicts of Interest}

The authors declare that they have no conflicts of interest.

\section{Acknowledgments}

The authors acknowledge the support from the Anhui University of Science and Technology, the high-level 
introduction of talent scientific research startup fund funding (13210027).

\section{References}

[1] X.-P. Feng, Z. Jia, and H. Liang, "A full air cooling and heating system based on mine water source," Applied Thermal Engineering, vol. 145, pp. 610-617, 2018.

[2] P. Y. Guo, G. L. Zhu, Y. Q. Liu, and J. Wu, "Field experiment on coalmine heat disaster governance using cold source from surface water," International Journal of Mining Science and Technology, vol. 24, pp. 865-869, 2014.

[3] P. Sasmito Agus, C. Kurnia Jundika, B. Erik, and M. Arun, "Computational evaluation of thermal management strategies in an underground mine," Applied Thermal Engineering, vol. 90, pp. 1144-1150, 2015.

[4] M. C. He, "Application of HEMS cooling technology in deep mine heat hazard control," Mining Science and Technology, vol. 19, pp. 269-275, 2009.

[5] W. Chen, S. Liang, and J. Liu, "Proposed split-type vapor compression refrigerator for heat hazard control in deep mines," Applied Thermal Engineering, vol. 105, pp. 425-435, 2016.

[6] M. C. He, X. L. Cao, Q. Xie et al., "Principles and technology for stepwise utilization of resources for mitigating deep mine heat hazards," Mining Science and Technology, vol. 20, pp. 20-27, 2010.

[7] R. Anderson and E. De Souza, "Heat stress management in underground mines," International Journal of Mining Science and Technology, vol. 27, pp. 651-655, 2017.

[8] X. J. Yang, Q. Y. Han, J. W. Pang, X. Shi, D. Hou, and C. Liu, "Progress of heat-hazard treatment in deep mines," Mining Science and Technology, vol. 21, pp. 295-299, 2011.

[9] X. B. Mao, L. Y. Zhang, T. Z. Li, and L. H. shun, "Properties of failure mode and thermal damage for limestone at high temperature," Mining Science and Technology, vol. 19, pp. 290-294, 2009.

[10] Y. N. Gao, F. Gao, Z. Z. Zhang, and T. Zhang, "Visco-elasticplastic model of deep underground rock affected by temperature and humidity," Mining Science and Technology, vol. 20, pp. 183-187, 2010.

[11] M. J. Li, Study of the Deformation Laws of Rock Roadways in Deep Mine Bases on Thermo-Mechanical Coupling, Anhui University of Science and Technology, Huainan, China, 2010.

[12] A. Parham, D. Williams Ian, S. Brian, P. Nicole, K. T. Hayden, and P. O. Claudia, "An octet-truss engineered concrete (OTEC) for lightweight structures," Composite Structures, vol. 207, pp. 373-384, 2018.

[13] H. C. Na, Analysis and Control of Rock thermal Damage Resource in Deep Mining, Central South University, Changsha, China, 2014.

[14] S. L. Xu, J. H. Liu, and Q. Zeng, “Towards better characterizing thermal conductivity of cement-based materials: the effects of interfacial thermal resistance and inclusion size," Materials and Design, vol. 157, pp. 105-118, 2018.

[15] V. Z. Zadeh and C. P. Bobko, "Nanomechanical characteristics of light weight aggregate concrete containing supplementary cementitious materials exposed to elevated temperature," Construction and Building Materials, vol. 51, pp. 198-206, 2014.

[16] P. Melo Javier and M. N. Flores, "Sepulcre Aguilar Alberto, et al. Rheological and thermal propertiesofaerated sprayed mortar," Construction and Building Materials, vol. 154, pp. 275-283, 2017.
[17] S. A. Alberto, P. Melo Javier, and H. O. Francisco, "Microstructural analysis of aera ted cement pastes with fly ash, metakaolin and sepiolite additions," Construction and Building Materials, vol. 47, pp. 282-292, 2013.

[18] G. X. Chen and K. Wang, "Mechanical and thermal properties of glass fibre-reinforced ceram site -foamed concrete," Indoor and Built Environment, vol. 27, pp. 890-897, 2018.

[19] Y. Zhang, G. Ma, Y. Z. Liu, and Z. Li, "Flexural performance of glazed hollow bead reinforced concrete beams," Journal of Reinforced Plastics and Composites, vol. 34, pp. 1698-1712, 2015.

[20] Z. Z. Jiao, Y. Wang, W. Z. Zheng, and W. Huang, "Effect of the activator on the performance of alkali-activated slag mortars with pottery sand as fine aggregate," Construction and Building Materials, vol. 197, pp. 83-90, 2019.

[21] G. Ma, L. Yan, W. K. Shen, D. Zhu, L. Huang, and B. Kasal, "Effects of water, alkali solution and temperature ageing on water absorption, morphology and mechanical properties of natural FRP composites: plant based jute vs. mineral-based basalt," Composites Part B: Engineering, vol. 153, pp. 398-412, 2018.

[22] S. P. Zhang, Y. Li, and Z. Y. Zheng, "Effect of physiochemical structure on energy absorption properties of plant fibers reinforced composites: Dielectric,thermal insulation , and sound absorption properties," Composites Communications, vol. 10, pp. 163-167, 2018.

[23] J. Y. Pang, J. K. Huang, W. J. Yao, and W. jin, "Experimental study on thermal conductivity and strength of thermal shotcrete in roadway," Journal of Yangtze River Scientific Research Institute, vol. 35, pp. 119-124, 2018.

[24] M. Li, S. X. Chai, H. Y. Zhang, H. P. Du, and L. Wei, "Feasibilityofsalinesoilreinforcedwith treated wheat straw and lime," Soils and Foundations, vol. 2, pp. 228-238, 2012.

[25] J. R. Zang and X. Q. Ou, "Research idea for high-performance thermal insulation lightweight aggregate shotcrete in high geo-temperature tunnel," Concrete, vol. 9, pp. 140-144, 2016.

[26] construction industry press, "Technical specification for application of sprayed concrete," Report JGJ/T372-2016, China construction industry press, Beijing, China, 2016.

[27] construction industry press, "Standard for test methods for mechanical properties of ordinary concrete," Report GB/T500812002, China construction industry press, Beijing, China, 2016.

[28] M. Lahouioui, R. Ben Arfi, M. Fois, I. Laurent, and G. Achraf, "Investigation of fiber surface treatment effect on thermal, mechanical and acoustical properties of date palm fiberreinforced cementitious composites," Waste Biomass Valor, vol. 11, pp. 4441-4455, 2020.

[29] P. W. Jiang, J. H. Fang, J. Y. Pang, and G. Liu, "Mechanical properties and micro-properties of plant fiber shotcrete," Journal of Yangtze Scientific Research Institute, vol. 37, no. 8, pp. 137-141,149, 2020.

[30] P. Zhou, Z. J. Wang, Y. Yang, and X. Ji, "Experimental study of the performance of basalt fiber shotcrete under heat damage," Journal of Civil Architectural \& Environmental Engineering, vol. 38, pp. 69-76, 2016.

[31] T. Hui-Yin, H. Bao-Huey, and W. An-Siou, "CombiningAHPandGRAmodel forevaluation property -liability insurance companies to rank," Journalof GreySystem, vol. 20, pp. 65-78, 2008.

[32] N. Zou, H. C. Pang, X. K. Zhu, and P. Tian, “Al(OH)3@AlPO4 composite flame retardant with hierarchical structure and its flame retardancy for pe," Enginnering Plastics Application, vol. 46, pp. 118-122, 2018.

[33] L. X. Zhu, T. Yue, S. Y. Gao, and S. P. Xia, "Hydrothermal crystal growth of $\mathrm{Mg}(\mathrm{OH}) 2 \bullet 2 \mathrm{MgSO} 4 \bullet 2 \mathrm{H} 2 \mathrm{O}$," Acta PhysicoChimica Sinica, vol. 19, pp. 212-215, 2003. 